\title{
EVOLUCIÓN, TRADICIÓN Y LIBERTAD ¿CÓMO CONFIGURARLAS PARA QUE LAS HABITE EL HOMBRE?
}

\section{ANDRÉS RECASENS SALVO}

\section{Antecedentes'}

Las reflexiones que anuncia el título del presente trabajo, son cuestiones que tienen su motivación en la esperanza de lograr una convivencia dentro de una unidad académica a la que pertenezco y que reúne a bioantropólogos, a arqueólogos, a prehistoriadores y a antropólogos sociales y, más aún, en una Facultad donde se desarrollan algunas de las disciplinas de las ciencias sociales. Esta convergencia buscada, que podría verse enriquecida por la realización de investigaciones interdisciplinarias, permitiría transformar fronteras en horizontes, promover cuestiones sobre el pensar de los otros desde nuestros diferentes puntos de vista, en donde la curiosidad y, por qué no reconocerlo, la necesidad, nos llevaría a acercarnos a los bordes de nuestra ciencia para observar lo que sucede en las otras disciplinas. Esta interdisciplinariedad se hace cada vez más posible por la pérdida de prestigio de los paradigmas convertidos en dogmas. Los nuevos paradigmas prefieren las dudas que plantea el círculo abierto a la engañosa certidumbre del círculo cerrado. Es común encontrarse con la proposición de un cuadrado al cual le ha sido desprendido un lado, o con un triángulo cuyo vértice superior no está sellado sino abierto a la curiosidad del firmamento. El antropólogo Roger Caillois (1959) decía que los eruditos, por el hecho de estar especializados en un dominio restringido de una disciplina, ocasionalmente "se hallan en condiciones de percibir un género de relaciones que solo un saber polivalente es capaz de establecer. (...) Ya es tiempo de tentar la suerte de las "ciencias diagonales". El escenario epistemológico en el cual nos movemos actualmente, responde a algunas preguntas, pero, al mismo tiempo, se abre a muchas interrogantes. Algo similar a lo que Martín Heidegger (1990) decía con relación a un seminario: "un lugar y una ocasión de arrojar aquí y allá una semilla, de dispersar un germen de meditación que, tal vez un día, se abra a su manera y fructifique".

Partiré eligiendo como punto central de este ensayo, una de las cuestiones que más ha incentivado mi curiosidad y que me ha llevado a atisbar a través de las membranas de lo vivo y a ensoñar sobre las jornadas a campo traviesa del hombre en la naturaleza, atravesando azares, selecciones e incertidumbres. Y miro hacia atrás, lo más atrás que mi intuición -a veces montada a horcajadas del conocimiento-, me permite. $Y$ presiento que detrás de la célula alguien me está observando y pesa mis acciones. Quizás, fue ese alguien el que se proporcionó mi cuerpo. El mismo que se fue construyendo cuerpos de una infinidad de formas a lo largo de miles de millones de años, hasta llegar hasta nosotros y constituirnos en su morada. $Y$ ese alguien en quien pienso, es el ADN. O, tal vez, alguien que está detrás de lo que conocemos como ADN. Y entrevero una finalidad, aunque no sepa claramente cuál es.

Cuando pienso en que Brian Goodwin dice, partiendo de la idea de Whitehead, que "la evolución es el avanzar creativo hacia la novedad", y asegura que la creación es una danza sin fin que

\footnotetext{
* Antropólogo Social. Licenciado en Antropología. Licenciado en Filosofía con mención en Historia. Profesor Honorario de la Universidad de Chile. Correo-e: arecasen@uchile.cl
} 
no va a ninguna parte; que la evolución no tiene objeto, ni sentido, ni dirección², tiendo a aceptar la posibilidad que la evolución no tenga ninguna idea hacia donde se dirige, pero no tengo dudas que sí la tiene Aquel que está detrás de ella. Si es así, ¿seremos acaso otra de las tantas estaciones que ese Ser se va construyendo, o somos la estación final de su viaje? Cualquiera que sea la respuesta, ya sea que se postule al Ser que somos como estación o como término, ambas me llegan como simplificadas, como no resolviendo lo que quisiera preguntarme, realmente. Me llegan como remansos deseados, quietudes imaginarias, como los ciclos poetizados por Schopenhauer: "la planta siempre reverdece y florece, el insecto zumba, y el animal y el hombre subsisten en su indestructible juventud, y cada verano encontramos de nuevo las cerezas saboreadas ya mil veces". Aquí, el filósofo recurre a la poesía para agregar la inspiración al razonamiento filosófico, dando así la razón a Descartes, quien encontraba más profundidad en los pensamientos de los poetas que en los de los filósofos; $y$, para afirmar su idea también poetizaba: "en el hombre hay semillas de ciencia -tal como en la piedra hay gérmenes de fuego-; $y$, mientras los filósofos sacan a éstas a la luz a través del razonamiento, los poetas las hacen resplandecer y volverse más luminosas gracias a su imaginación." Pienso que en el concepto de imaginación que utiliza Descartes, subyacen don conceptos que son los que tienen que ver más directamente con la poesía: la intuición y la inspiración ${ }^{3}$.

Busquemos por otro sendero. Edgar Morin (1971) nos lleva a preguntarnos ¿qué es la vida? ¿Qué es el hombre? Esta doble interrogación dice-, retoma uno de los grandes diálogos entre los dos centros de todo saber: por una parte, la corteza cerebral humana; $y$, por otra parte, el ADN.; el uno consciente, pero tanteando, igno- rando absolutamente lo que pasa en el sistema que lo ha producido y de las potencialidades con que lo proveyó la naturaleza; y, el otro, inconsciente, pero disponiendo de un tesoro fabuloso de conocimientos y de organización, pero todavía sumergido fuera del alcance de la corteza cerebral como para que pueda ser procesado como información.

Entonces, el cuerpo no sería otra cosa que extensiones creadas por el Ser y que le informan del mundo. Parapetado tras el cráneo, inviolable fortaleza del cerebro, maneja la información y ordena las exploraciones tendientes a obtener los recursos para reemplazar la energía, el combustible para su funcionamiento y el de sus extensiones mismas. La maquinaria que lo traslada, le permite manipular el medio y le proporciona información para evaluar los resultados y distinguir los aciertos y los fracasos. Calcula la temperatura, la luz, las formas y textura de lo de afuera. Formula preguntas y evalúa respuestas. De ese modo va estructurando en el adentro el afuera que va construyendo a medida que éste reacciona a sus demandas. Su primera orientación es hallar, haciéndola, su morada. La que habitará con aquella que debe conocer para continuarse y continuarla.

El biólogo R. Dawkins (1996) nos dice que desde la perspectiva del gen humano, a quien llama "gen egoísta", somos máquinas de supervivencia robotizadas, puesto que los genes no pueden atrapar y comer cosas o salir corriendo por sí mismos, por lo que están obligados a valerse de intermediarios; yo diría por extensiones, unas para pensar y otras como instrumentos. Dawkins afirma que los genes tienen que construir máquinas que hagan estas cosas por ellos. En sus clases en Oxford, a fines de los sesenta, enseñaba a sus alumnos a que: 
“(...) pensaran en los animales como máquinas que portaban sus instrucciones; (...) así, sus miembros -dedos y pies- eran palancas para impulsar los genes hasta la siguiente generación (...) como un robot provisto de cerebro, ojos, manos, etc. El animal lleva consigo su propio programa, sus propias instrucciones" (70-71).

De manera que según Dawkins: "El éxito evolutivo consiste en confeccionar programas que no naufraguen. Los programas que naufragan no se perpetúan" (74). Como vemos, Dawkins no tiene dudas de que el gen es el que está a cargo del vehículo. Más adelante, intuyo que puede estar haciendo el Galileo frente a los inquisidores de su comunidad científica: "Estoy de acuerdo en que la evolución nunca estuvo orientada en ningún sentido hacia alguna distante meta de la humanidad. Eso es un disparate, y a ningún evolucionista serio se le pasaría por la cabeza" (Ídem).

Rumi el Sufi, poeta y místico del siglo XIII, con la sabiduría de un filósofo responde desde el pasado al biólogo, en una síntesis profunda: "No existe otra causa final salvo el hombre. Está revelada en el propio ser del hombre"4.

¿Cuál ha sido la razón de que los esfuerzos del hombre hacia lo profundo de la tierra no hayan sido más que instrumentales, una búsqueda de recursos para afianzar su mirada hacia arriba? Lo abisal, estigmatizado desde siempre como el lugar en donde se asienta el castigo, donde triunfa el mal. Como el triunfo del cielo sobre el infierno y, por ende, derrota de la espeleología. Por esta razón, la totalidad de los esfuerzos del hombre en la indagación acerca de su pasado, están orientados hacia el universo.

El Rabí M. Méndel de Kotzk (1994) dejó a sus discípulos una bella alegoría:

\begin{abstract}
"Las almas descienden del reino de los cielos por una escalera. Luego ésta es retirada. Pero desde arriba llaman a las almas para que retornen. Algunas no se mueven de su lugar porque, ¿cómo subir al cielo sin escalera? Otras saltan y caen y saltan nuevamente y abandonan. Pero están aquellas que saben muy bien que no es posible lograrlo, pero lo intentan y lo intentan una y otra vez hasta que Dios las toma en sus manos y las eleva a las alturas".
\end{abstract}

\section{II. ¿Pero cuál es el destino del Hombre? Por último ¿cuál es mi destino?}

Con el hombre, comienza un viaje y una aventura fascinantes. Desde el comienzo el lenguaje y el pensamiento parten imbricados, sacan chispan y lanzan bengalas al entendimiento. Desde los gritos guturales de asombro, de terror o de alegría se fueron desgajando los fonemas para juntar palabras y luego oraciones; y después frases y relatos, estructurando mitos, todos frutos del hombre recogidos en su interactuar con el mundo. Frutos que se encanastan formando la tradición oral, foco para observar el mundo y observarnos a nosotros mismos en el mundo.

Y así quiso el hombre iniciar una aventura por su cuenta, inmerso en la novedad de un mundo hecho, plataforma desde la cual él debía hacerse un mundo, su mundo. $Y$, al decir por su cuenta, no puedo menos que plantearme la idea de la libertad del Hombre. Y me extenúa el revisar lo agobiador y decepcionante que ha sido siempre tratar de encarnar esta Idea. Y si ésta no se entendiera en toda su magnitud y sobrecogedora profundidad, es cosa de volver la mirada hacia el pasado, al siglo XV, y escuchar al humanista florentino Giovanni Pico della Mirandola, quien, adoptando la voz del Creador, nos anunció un destino prodigioso, pero que conlleva una responsabilidad plena de angustias y zozobras. Atendamos a su mensaje: 


\begin{abstract}
"No te he dado ni rostro ni lugar alguno que sea propiamente tuyo; ni tampoco ningún don que te sea particular -¡Oh Adán!-, con el propósito de que tu rostro, tu lugar y tus dones seas tú quien los desee, los conquiste y de ese modo los poseas por ti mismo. La Naturaleza encierra a otras especies dentro de unas leyes por mí establecidas. Pero tú, a quien nada limita, por tu propio arbitrio, entre cuyas manos yo te he entregado, te defines a ti mismo. Te coloqué en medio del mundo para que pudieras contemplar mejor lo que el mundo contiene. No te he hecho ni celeste, ni terrestre, ni mortal, ni inmortal, a fin de que tú mismo, libremente, a la manera de un buen pintor o de un hábil escultor, remates tu propia forma" (Yourcenar, 1991:12).
\end{abstract}

Esta libertad que se nos asigna como destino, digna hija del Renacimiento, supera cualquier posterior proposición hecha al Hombre. Libertad que el Hombre ha tomado más como un castigo que como una dádiva, por el esfuerzo sobrehumano que implica. ¿Qué rostro? ¿Qué destino? ¿Cuál debe ser mi perfil en el marco del universo, si ya no basta la máscara terrestre que se me ha dado? ¿Cómo superar esta sensación de vacío que me inunda, al solo pensar en la tarea que me supone llegar a ser el Ser que Soy? El potencial que nos adjudica Giovanni Pico della Mirandola es maravilloso, pero tan aterrador como el ofrecimiento de un viaje al espacio sin cápsula, sin traje espacial, un cuerpo desnudo sorteando meteoritos.

En la primera mitad del siglo XVII se otorgaba una permisividad al escritor y poeta Cyrano de Bergerac, que en el siglo XIX no se le iba a conceder al científico Charles Darwin, aún cuando el poeta fue mucho más allá de lo que habría podido siquiera imaginar el científico. Tal vez, porque el primero tuvo la precaución de enmascarar su escrito bajo el título Histoire comique d'un voyage á la Lune... A Cyrano de Bergerac le preocupaba la multiplicidad de ordenamientos celulares que fueron constituyendo la fisiología de lo vivo hasta el ser humano. Más aún, piensa a la materia "encaminándose al dibujo del hombre", imagen ésta de una gran hermosura, comparable a lo que expresará tres siglos después Teilhard de Chardin acerca del "poder espiritual de la materia", y cuando declara su "irresistible simpatía por todo cuanto se agita dentro de la masa oscura de la materia”. El teólogo jesuita y paleontólogo considera que la historia humana, y aún de la Tierra, es solo un segmento modesto de un proceso cósmico glorioso que comenzó con la aparición de la vida y que continuará durante billones y billones de años, hasta que en la más lejana de las galaxias se proclame a Cristo como Logos. En verdad, Teilhard de Chardin, fe y confianza en una creación que armoniza universo, vida y hombre. Es desde esa síntesis que declara que el hombre es "materia hominizada". Desde una perspectiva distinta, pero no menos hermosa, Einstein hace converger la vida humana en todo lo viviente, en un solo y cálido abrazo. En una oportunidad en que estuvo gravemente enfermo, la esposa de Marx Born le preguntó si tenía miedo a la muerte. Este respondió:

\footnotetext{
"-No. Me siento tan solidario con todo lo viviente, que me es indiferente donde empieza y acaba cada individuo" (Born \& Hedwig, 1971).
}

Pero volvamos a Cyrano de Bergerac. El dice que en este caminar hacia el dibujo del Hombre, se formó la piedra y el plomo, el coral y la flor y, también, el cometa; camino éste que trasciende lo vivo y recorre los senderos del cosmos. Camino que no está hecho de antemano en el plan de nadie, sino en brazos del desorden, del azar, de tal modo que "no se sabrá lo poco que ha faltado para que no se hubiera hecho el hombre." Leamos cómo lo dice el autor: 
“(...) Y, después de esto, os extrañáis de que esta materia, revuelta en desorden y al azar, pueda haber constituido un hombre, teniendo en cuenta que había tantas cosas necesarias a la construcción de su ser. ¿No sabéis, pues, que un millón de veces esta materia, encaminándose al dibujo de un hombre, se ha parado a formar ya una piedra, ya plomo, ya coral, ya una flor, ya un cometa, y todo esto debido a la mayor o menor cantidad de ciertas figuras que se necesitaban o no se necesitaban para diseñar un hombre? No es, pues, una maravilla que entre una infinidad de materias que cambian y que se remueven incesantemente hayan encontrado el medio de hacer los pocos animales, vegetales y minerales que vemos, como tampoco es ninguna maravilla que en cien jugadas de dados haya una en la que salen los tres con el mismo número; más aún, es imposible que de ese movimiento no se haga algo, y este algo será admirado siempre por un atolondrado que no sabrá lo poco que ha faltado para que no se hubiera hecho" (Calvino, 1995: 32).

Antes que los anteriores autores, en el siglo XIII, Rumi el Sufi, enseñaba que el verdadero Ser no deviene de lo que el medio y la cultura desarrollan en nosotros, sino que es, básicamente, el producto del universo en evolución; razón por la cual se le denomina ser cósmico o ser universal, en contraste con el ser fenoménico, que es el producto de la cultura y el ambiente:

"El ser cósmico puede ser considerado como la imagen del universo que debe ser develada (...), mientras que el ser fenoménico designa solo una parte de nuestra existencia (...), el ser cósmico nos abarca totalmente; El ser fenoménico nos ha separado de nuestro origen, el de la unión con la vida (...), el hombre estuvo una vez unido a la naturaleza en el estado animal, y aun más así en sus formas anteriores como vegetal o mineral, alcanzando finalmente la composición básica de la naturaleza"(Arasteh, 1984).

Hay en las epístolas paulinas una exhortación a revestirnos del hombre nuevo; a dejarnos renovar una y otra vez por el espíritu que actúa en nuestro interior y, para conseguirlo, tenemos que despojarnos del hombre viejo. El espíritu es el que orienta nuestras acciones para el regreso que llevará al último Adán a ser el primer Adán, pero espiritualizado. Pues el primero fue hecho de tierra porque en la Tierra fue logrado. El segundo hombre es celestial pero llevará la imagen del terreno ${ }^{6}$. En otra parte yo había sugerido: "¿a qué fin las máquinas para elevarnos/ si era el espíritu/ quien daría las alas?"(Recasens, 1993).

¿Pero quién fiscaliza este estar-siendo-hechos y nuestro hacernos?¿Dónde está el Juan Bautista de estos tiempos que formule la pregunta: "- ¿Eres Tú el que debía venir, o debemos esperar a Otro?" ¿. ¿Y quién responderá ahora? O, simplemente, veremos cómo nos escribe Dios, nuevamente, la sentencia en la pared del palacio de Baltasar, rey de los caldeos: Mane, Thecel, Phares. Debiendo nosotros asumir la segunda: "fuiste pesado en la balanza y hallado falto de peso"8.

\section{Pero el Hombre es hombre porque es un ser cultural}

La Cultura se puede proponer como un sistema de Ideas y de Acciones, en donde las primeras van configurando una imagen del mundo y, las segundas, van estructurando un estilo de vida. Las ideas nos proveen de orientaciones para nuestras acciones y estas retroalimentan a las ideas según las experiencias, y viceversa. Las acciones del hombre tienden a culminar en realizaciones, desde un alfiler hasta una nave espacial; desde una pareja humana hasta las grandes organizaciones e instituciones internacionales; y desde un grito de temor frente a un puño, hasta un poema. Cada cultura define a su manera un modo de vida que le es 
peculiar, y dentro de ella el hombre procura acomodarse a los patrones de la cultura en que se desenvuelve; a veces, adquiere la convicción de que el comportamiento exigido es el deseable y correcto; otras, solo obedece, esperando la ocasión para presionar por un cambio. Así, no está sujeto de modo estricto e irremediable a ninguna modalidad de pensamiento o de conducta, pudiendo adoptar otras, siempre que exista en la sociedad que vive la flexibilidad adecuada para disentir $u$ ofrecer alternativas. En síntesis, la cultura nos provee de formas de pensar, de ver, de hacer y de objetivar en el mundo, y desde las interacciones con éste, pueden surgir recomendaciones que nos sugieran dejar de lado algunas formas, estabilizarnos en ellas, revisarlas o crear nuevas formas. Todo lo cual es posible y deseable, siempre que no se haya dejado domesticar.

Rumi el Sufi enseñaba que el solo tomar conciencia del poder del amor y de vincularse con otros no basta; y que el hombre debe verter su estado de ser, la bondad, la benevolencia y el amor en la conducta humana y la creatividad. Rumi vuelve supremo el poder del amor y, de este modo, hace del amor entregado por el hombre un medio para lograr la camaradería y el bienestar" (Arasteh, 1984).

La idea que el hombre se hace del Hombre, según el antropólogo M. Landmann, llega a convertirse en un modelo a seguir, en un Ideal por el cual trata de regirse y mediante el cual se modela. El hombre es el ser que se ha de construir a sí mismo y por eso busca una imagen rectora sobre la cual construirse. Ambas cosas, construcción de sí mismo e imagen rectora o modelo se enlazan una a la otra en lo que Edgard Morin llama la auto-eco-construcción ${ }^{9}$. El Rabí laacov Itzjac de Pzhysha (El
Hiehud) dijo: "Los ángeles tienen sus virtudes y sus defectos. La virtud de los ángeles consiste en que no pueden deteriorarse, y su defecto es que no pueden mejorar. El defecto del hombre es que puede deteriorarse, y su virtud, que puede mejorar"10.

\section{Pero persiste un sentimiento pesimista que se carga sobre los hombros de nues- tra especie y de nuestra cultura}

Desde hace tiempo que el Hombre ha comenzado a desconfiar y a recelar de sus fuerzas, y tiende a abandonar la tarea de construirse a sí mismo y desde sí mismo, para recurrir a sus propias creaciones científicas y tecnológicas transformando el signo de la Creación que porta. $Y$ a pesar de las advertencias y reproches de los pensadores que lo instan a cambiar de rumbo, persiste en sus manipulaciones. Uno de los detractores del camino hasta ahora seguido es Max Born, Premio Nobel de Física en 1954, quien expresaba su impresión de que el intento de la naturaleza de crear en este mundo un ser pensante había fracasado. Lo explicaba así:

"(...) el hombre está convencido, por la capacidad de su cerebro, de su superioridad sobre todos los demás seres vivientes; sin embargo, dudo que, en esta concienciación de sí mismo, sea más feliz que los restantes animales. Solo han transcurrido algunos milenios de su historia, que está repleta de acontecimientos apasionantes, pero que considerada en su conjunto resulta monótona: la paz alterna con la guerra, la construcción con la destrucción, la prosperidad con la decadencia...una criatura en la que se confunden instintos animales y fuerzas intelectuales" (Born \& Hedwig).

Lo que plantea el físico como fracaso, no es tanto acerca del hombre como "pensante", sino que el fracaso se produce por no ser el hombre moral que se espera que sea. 
Este pesimismo que se carga sobre los hombros de nuestra especie y de nuestra cultura, me hace recordar un sentimiento de pesimismo expresado por algunas sociedades indígenas del sudeste americano, en los albores del siglo veinte. Para los guaraníes, la humanidad, como la Tierra misma, estaba cansada de vivir y quería descansar. Los apapocuvás-guaraníes expresaban que el aniquilamiento del mundo era una consecuencia de que la Tierra estaba vieja y de que su raza no se seguiría multiplicando: "volveremos a ver a los muertos, vendrán las tinieblas, los murciélagos nos tocarán con sus alas, todos los que todavía quedemos sobre la Tierra llegaremos a nuestro fin". La idea central de esta creencia es la de la fatiga cósmica, el agotamiento universal. Según relataba un chamán perteneciente a dicha etnia, una visión lo transportó a la presencia del gran Dios, y ahí había escuchado a la Tierra implorar al Señor, para que pusiera fin a sus creaciones: "Estoy exhausta", suspiraba la Tierra, "me he atracado con los cadáveres que devoro. Permíteme descansar, Padre". Las aguas también imploraban al Creador que las dejara descansar, y también los árboles, y toda la naturaleza. Es una expresión conmovedora de la fatiga cósmica y la nostalgia por el descanso final. Nimuendajú, dice que la migración de los grupos guaraní hacia el Este, hacia el nacimiento del sol, no se debió a conflictos bélicos con tribus enemigas, ni tampoco a la esperanza de encontrar mejores condiciones de caza y recolección al otro lado del río Paraná, ni tampoco se trató del deseo de acercarse a la civilización traída por los portugueses. La motivación era nada menos y nada más que el temor de la destrucción del mundo y a la esperanza de alcanzar la "Tierra sin Mal" antes de dicha destrucción. Lo anterior me hace pensar sí habrá sido una motivación similar la que impulsó el exilio del pueblo maya. Según Mircea Eliade, lo que se da en llamar "pesimismo indio", tiene su origen en una creencia generalizada entre los pueblos primitivos, que se podría resumir de este modo: El mundo degenera por el simple hecho de que existe y debe ser periódicamente regenerado, es decir, creado de nuevo; por lo tanto, el fin del mundo es necesario para que pueda haber una nueva creación. Es probable que los apapocuvá-guaraníes hayan sustentado una convicción similar antes de la conquista europea y la conmoción producida por el contacto debe haber agravado e intensificado el deseo de escapar de un mundo de miseria. Igual que muchos otros pueblos primitivos, los guaraníes anhelaban vivir en un cosmos puro, nuevo, rico y bienaventurado. El paraíso que buscaban es el mundo restaurado a su belleza y gloria primitivas: según ellos la "Tierra-sin-Mal o la casa de Nandé ("La casa de Nuestra Abuela") existe aquí, en la Tierra (...) está en este mundo (...) no pertenece al más allá (...) está muy bien escondida. No se llega (...) en alma y espíritu, sino en carne y huesos"11.

\section{Pero el Hombre es un ser que se va pros- cribiendo de sí mismo, en un progresivo extrañamiento para hacer de Sí un Otro.}

Al margen del conocimiento público, los científicos han sido vencidos por la tentación de pasar de la manipulación genética en animales a la manipulación genética en seres humanos. Sobran los conejillos de Indias: marginales de variado tipo como serían los pobres, drogadictos, presos, migrantes indefensos del Tercer y Cuarto mundos. En 1995, la Ministra de Justicia de los Estados Unidos reconoció en una entrevista en televisión, la utilización de deficientes mentales por parte del ejército de dicho país, para experimentos sobre los efectos de la radiación en los seres humanos, específicamente, en soldados. La historia de los experimentos hechos por los labo- 
ratorios del mundo desarrollado, en las sombras para no mostrar su inhumanidad, es algo que debiera ser investigado por las organizaciones de derechos humanos. En un laboratorio europeo se creó un embrión que era el fruto del cruce entre un hombre y una hembra chimpancé que había recibido esperma humano para su fecundación. En los Estados Unidos, el mismo tipo de fecundación se realizó ya no in vitro sino en vivo; pero la chimpancé habría desarrollado su embarazo durante un mes y luego habría abortado (Kovacs, 1977). Las explicaciones científicas acerca de las varias tecnologías biomédicas, adelantan sin mesura posibilidades e intenciones con respecto a una nueva génesis del hombre. Que el control científico que se pretende sobre las potencialidades de lo humano implica no solamente la cantidad sino también la calidad de la vida conforme a consideraciones eugénicas y terapéuticas. Según las declaraciones que leemos y escuchamos continuamente, el objetivo fundamental es asegurar la preservación y la difusión de las estructuras genéticas 'preferidas', por medio de un control cualitativo de la reproducción del organismo o por la creación científica de nuevos procesos reproductivos (Op.cit.) A no dudar, en el camino irán quedando como testigos de esta búsqueda una plétora de intentos de remedos aberrantes del Hombre Nuevo Anunciado por la Ciencia. No sería extraño encontrar durante el tercer milenio, una de ese bar de la película La Guerra de las Galaxias, pero no con la diversidad de formas venidas de diferentes planetas del universo, sino de productos debidos a la diversidad de deformaciones surgidas de intervenciones malogradas, por parte de una ingeniería genética que incursionó más en el surrealismo que en una experimentación científica responsable. ¿Acaso no se recuerdan las monstruosas experimentaciones del Dr. Moreau en la novela de H.G. Welles?
El 23 de febrero de 1997, fue anunciado el nacimiento de la oveja Dolly, siete meses después de haber ocurrido éste. Se trataba del primer mamífero clonado a partir de una célula adulta. Este método consiste en realizar -in útero o in vitro-, copias exactas de seres vivos. ¿Estaremos en la avant premier de los tiempos anunciados por Aldous Huxley en su Mundo Feliz? Desde esa fecha, han sido variadas las opiniones vertidas sobre este suceso por científicos, teólogos, humanistas y otros. Pienso en un problema que no se ha abordado y que se le plantea a las personas que pertenecen a las religiones de mayor influencia en el mundo. Todas aquellas que se refieren a la persona como un ente responsable de sus actos frente a la divinidad. Es la persona la que, por sus obras, recibirá premios o castigos. De aquí me surge una duda: ¿el ser original traspasa a los clones su personalidad y su responsabilidad moral? Pienso que no, ya que, aún siendo copias exactas del original, el desarrollo de sus personalidades depende en gran medida del medio ambiente en que se desenvuelven. Y así, cada uno obtendrá una biografía personal distinta. Por otra parte, los clones están libres de responsabilidad, porque no pertenecen a la creación de Dios y no reciben el soplo divino. ¡Qué inútil sería bautizarlos! Cabe, entonces, recordar la sentencia de Iván Karamazov: "-Si Dios no existe, ¡todo está permitido!". Así, clones y androides futuros no están sujetos a restricciones morales porque no están incluidos en la salvación. Peligroso será si cuando constituyan un número apreciable de entes, alguien se los recuerde o ellos mismos lo reflexionen. $\mathrm{Y}$, si descubren que no tendrán acceso a cielo de ninguna clase, se les podría generar un gran rencor que buscará venganza sobre sus originales. 


\section{Pero desde el propio seno de la Cien- cia surgen apelaciones por una mayor prudencia}

Lo anterior me lleva a recordar la lectura de un informe sobre un Simposio realizado al comenzar la década de los años 1970, en Basilea, Suiza, el que encuentro muy atinente a lo que he planteado más arriba. Además, es un acontecimiento que tiene que ver con lo que está sucediendo hoy en día. Durante un debate, Salvador Luria, Premio Nobel de Medicina, preguntó a la audiencia: “¿Estamos verdaderamente seguros de desear que se admita, en el mundo entero, la necesidad de decidir quién debe nacer?". Y, en seguida, se entabló un tenso diálogo entre F. Clarke Fraser, genetista canadiense, y Philip Handler, bioquímico y, en esos años, Presidente de la Academia Nacional de Ciencias de los Estados Unidos:

C. Fraser: “(...) -Nos tocará pensar en las nuevas medidas que tendrán que tomar los gobiernos y los hombres políticos para favorecer una selección positiva".

Ph. Handler: "¿Piensa usted en algún mecanismo capaz de determinar una selección positiva?"

C. Fraser:"(...) Yo creo que nos veremos obligados a admitir que hay cualidades deseables y otras que no lo son, y habrá que elegir".

Ph. Handler: "¿Quién va a decidir?"

C. Fraser: "¿La sociedad!"

Ph. Handler: "¿Y esta selección se basaría exclusivamente en ciertas cualidades mensurables de los padres? (...) ¿Quiere usted decir que habría que procurar aumentar, en la población, la aparición de características que usted, u otra persona autorizada, considera como deseables?"

C. Fraser: "Yo sí creo que hay ciertas aptitudes sobre cuya deseabilidad se está generalmente de acuerdo. Podría concebirse un aliciente que incite a la gente a adoptar un comportamiento selectivo de reproducción con respecto a tal o cual aptitud particular. Nuestro actual sistema de subsidio familiar tiene el efecto contrario".
Salvador Luria interrumpe la discusión, exclamando:

\footnotetext{
“ ¡Me parece que lo que usted acaba de decir, es el argumento más contundente para que hagamos cuanto esté en nuestro poder, a fin de encontrar otros medios de regular la natalidad, porque uno de los peores peligros que entraña la superpoblación es, precisamente, que lleguen a admitirse algún día proposiciones semejantes!".
}

Han transcurrido cuatro décadas desde esta discusión. ¿Quién podría pensar que los científicos representados por C. Fraser aceptaron e hicieron suyas la proposición ética de $\mathrm{S}$. Luria y Ph. Handler? O, lo que es más seguro, se siguieron realizando investigaciones buscando alcanzar los objetivos planteados por el genetista canadiense, ya sea financiadas por corporaciones privadas o por gobiernos, cuyas intenciones y resultados se mantienen ocultos.

\section{Pero la Ciencia no puede pretender ser un río aparte del caudal original e inte- grador de la Cultura}

A contar de la segunda Guerra Mundial se ha estado ejerciendo una presión sobre los jóvenes estudiantes a fin de que vuelquen sus intereses en la universidad dentro del marco de las Ciencias Básicas, no solo en desmedro de las Ciencias Humanas, sino de espaldas a ellas, a las que algunos consideran triviales e inútiles para el crecimiento económico y el desarrollo industrial. De este modo, se pretende desconocer la importancia que ha tenido para la humanidad el desarrollo obtenido por la cultura en los últimos diez mil años. Este proyecto, que primó fuertemente en las décadas de los años 1950 y 1960, lo que estaba procurando era medir la modernización de un país de acuerdo a la densidad de científicos básicos por kilómetro cuadrado. 
P.B. Medawar decía la gente sufría de envidia de la física y que anhelan que su disciplina fuera considerada difícil, aun cuando no lo fuera. Que a veces se cae en el error de hacer complicado lo simple para impresionar, equivocando el camino, pues de lo que se trata es hacer simple lo complejo.

Un ejemplo del desprecio de la ciencia por las humanidades, es lo manifestado por Roger Schank, que transcribo a continuación, pues da la sensación de un niño al que se está obligando a tomar aceite de ricino:

"El caso es que yo soy un informático fenomenal y nada corriente en absoluto. Lo curioso de esta gente del mundillo literario es que por la razón que fuere piensan que si uno no ha leído a los clásicos carece de instrucción, mientras que a ellos no tener ni idea de ciencia les da lo mismo. (...) Para no complicarme la vida he acudido a un prontuario de Adler titulado The Syntopicon. He podido encontrar referencias de Tomás de Aquino, Montaigne y Aristóteles -los autores que Adler ha listado en el apartado "conciencia"-. Todos tienen una noción ambigua de la conciencia con un tinte religioso. En un académico de ahora sus reflexiones no serían nada del otro mundo. Aun así se nos repite que hasta que no los hayamos leído no seremos personas instruidas. Bueno, yo estoy leyéndoles y, la verdad, no me están enseñando gran cosa”.

Por su parte, J. Doyne Farrner reconoce que los físicos que llevaron a cabo las grandes revoluciones de los años veinte tenían en general una buena educación en filosofía. Que Einstein, por ejemplo, citaba a Kant con frecuencia, y consideraba que la instrucción filosófica era importante para un físico. Pero, sin embargo, reconoce que su generación creció oyendo no solo que la filosofía era algo en lo que no se debía perder tiempo, sino que ejercer de filósofo podía acarrear serios problemas. Más aún, el hecho de publicar un artículo en una revista filo- sófica -o, peor aún, escribir un libro para el gran público suponía poner en peligro la reputación del que se atreviera a hacerlo.

W. Daniel Hillis al referirse al biólogo chileno Francisco Varela, reconoce que es verdad que gente perfectamente válida para la inteligencia artificial se ha "perdido en la filosofía y ha dejado de hacer cosas útiles." Recuerda como si fuera un ejemplo a seguir por los científicos, que:
"(...) a M. Minsky le ha sentado muy mal que uno de sus discípulos favoritos, Tery Winograd, comenzase haciendo programas perfectamente buenos y haya acabado escribiendo un libro sobre hermenéutica (...) Minsky ve a la filosofía como un agujero negro que se está tragando a sus discípulos"12.

Lo que me hace pensar que la solución viene desde las generaciones jóvenes de científicos. Sin embargo, Steven Jones, confiesa el mismo cierre hacia las Ciencias Humanas:

\begin{abstract}
"Yo diría que los científicos tienen un problema (...) incertidumbre de la vejez es probablemente un término mejor-, de golpe uno olvida que la ciencia es el arte de lo contestable y comienza a especular sobre cosas que básicamente están fuera de ella. Nick Humphrey se mete en terrenos que no me parecen interesantes. La conciencia, el sentido de la vida, son cosas que siempre me han dejado frío".
\end{abstract}

Esto último hace que mi confianza flaquee, y me suma en la pesadumbre, pues lo que Humphrey había planteado era lo siguiente:

\footnotetext{
"¿Qué es lo que nos hace ser nosotros mismos? ¿Cómo puede el pedazo de materia que es un ser humano, constituir la base de la experiencia que cada uno de nosotros reconoce como su propio ser? ¿Cómo pueden un cuerpo y un cerebro humanos ser, además de eso, una mente humana?"13
} 
A mi juicio, todo esto es, francamente, muy desalentador. Estimo que la Ciencia debe ser considerada en el seno de la totalidad de la Cultura de un pueblo, de una civilización, como uno de sus tantos componentes. Pues, el conocimiento científico representa en el tiempo, solo la última realización conquistada por el hombre, en el ámbito de la capacidad y necesidad cognoscitivas propias de toda cultura humana. De ahí que el desarrollo de la Ciencia debe tender a interactuar con los demás componentes de la Cultura, y no pretender destruirlos, estigmatizarlos, desvalorizarlos 0 relegarlos a un rincón del quehacer humano. Le sería muy provechoso a la ciencia no olvidar que esto le sucedió a ella misma en siglos pasados. El retraso sufrido por ella por efecto de los prejuicios de que otrora fuera objeto, parece ser un buen ejemplo de cómo ella podría ser culpable ahora de la misma falta. La crisis se produce siempre que un determinado componente de la Cultura obtiene, por buenas o malas artes, una primacía con relación a los otros, e incurre en el pecado de soberbia al olvidar que solo el conjunto de ellos constituye la realidad total del Hombre.

La historia nos muestra las continuas luchas fratricidas entre los diferentes componentes de la Cultura: en Grecia, no fue Anitos el que hace morir a Sócrates, es la Política la que hace de verdugo de la Filosofía; y, después, en Roma, promueve el asesinato de Cicerón y el suicidio de Séneca. Vimos cómo la Religión humilló a la Ciencia en la persona de Galileo. ¿Y cómo olvidar las desdichadas muertes de Miguel Servet, Giordano Bruno y de Tomás Moro? Los dos primeros quemados en la hoguera a causa de la discordia entre la Religión y la Ciencia; y, el segundo, decapitado debido al divorcio entre el
Poder Político y la Moral. Hace algunas décadas vimos cómo la Ciencia, dando la espalda a la Ética, se comprometió con la Tecnología de la Guerra para convertir en antorchas a cien mil hombres en Hiroshima. También, cómo la Ideología, en las manos de Lisenko, persiguió a los investigadores soviéticos en el campo de la genética, acusándolos de herejía ideológica. A veces, vemos cómo la Ley trata de enmascarar su bastardía para imponerse en contextos socioculturales que podrían rechazarla por ilegítima. Y, para terminar con estos pocos ejemplos, preocupa observar cómo la Economía pretende asumir la Sociedad toda y a todo el Hombre, ignorando la diversidad de pueblos, de hábitos, costumbres, creencias y valores culturales.

En el trasfondo de lo anterior, está la presencia de una crisis de valores; crisis en el científico irresponsable, en el creyente fanático, en el político dogmático y corrupto, en los medios de comunicación de masas que, cuando no son cómplices, callan y no denuncian; y en el público-masa que prefiere y agradece no ser informado o que le "filtren" o censuren la realidad. A propósito de lo anterior, me permitiré una digresión: recuerdo lo sucedido a Epiménides, poeta y profeta del siglo VII a. C., que habiendo salido una tarde al campo para buscar una res extraviada, se separó del camino y entró a una cueva donde durmió un rato. Y, cuando salió de ésta, se encontró con que todo había cambiado, y fue a su casa y ahí no le reconocieron. Y su hermano, al que había dejado pequeño al salir al campo, estaba ya anciano. Por cálculos que pudo realizar, había dormido cincuenta y siete años. Lo que encuentro una impresionante anécdota, que de pasar hoy en día habría permitido imputar al cretense un "encuentro del tercer tipo", y la cueva no habría sido otra cosa 
que una nave espacial ¿Quién sabe? Pero si la anécdota ha llegado hasta nosotros después de dos mil seiscientos años, es porque en esa época no existía la NASA.

Sin embargo, no se trata de detener el avance de un componente de la Cultura, o de propiciar la utopía de un desarrollo similar de todos y de cada uno al mismo tiempo. Se trata solo de pedir una convergencia hacia una actitud científica moral, cultural y racionalmente fundada. Pedir, por ejemplo, que el desarrollo de la Ciencia se realice escuchando los consejos de la Ética y de la Moral; que atienda a la Filosofía, pero que, fundamentalmente, descubra al hombre que pretende afectar, cuando éste palpita emocionado frente a una obra de Arte. Que el científico busque su origen y desarrollo a lo largo de la Historia y descubra su identidad humana. $Y$ que, por su parte, hagan lo mismo el político, el religioso, el ideólogo y el militar. Pues el avance exponencial de la tecnología alimentada por la ciencia, hace no solo recomendable, sino imperativa una moralización de las instituciones que tienen la responsabilidad sobre dicho avance. No obstante, no hay consenso para esta propuesta en algunos científicos actuales de influencia en los medios académicos y profesionales.

Las obras de arte y de literatura, los sistemas religiosos y filosóficos, son objetivaciones culturales del todo evidentes; son diferentes maneras con las que el Hombre concreta en el mundo sus experiencias de interioridad y de exterioridad. No se puede pretender que aceptemos que la racionalidad de uno implique necesariamente la irracionalidad de los otros. La racionalidad es un horizonte humano que se extiende a todas las categorías y actividades, pues si hay ciertamente una racionalidad científica, también hay una racionalidad estética, o metafísica. De tal forma, que se hace imperativa una comunicación franca y respetuosa entre las diferentes áreas del conocimiento.

¿Acaso no son representantes válidos de una necesaria integridad cultural del Hombre, por ejemplo, un Goethe que, a la vez que escritor, fue un metódico estudioso de las ciencias naturales? ¿O un pintor y escultor como Leonardo Da Vinci, que fue también ingeniero y arquitecto? $Y$ en la época contemporánea ¿No suenan inequívocos los llamamientos a esta integridad por parte de un físico y filósofo como Max Born? ¿De un científico y teólogo como Teilhard de Chardin? ¿No deja obsoleta la dicotomía entre Ciencia y Filosofía el notable físico Werner Heisenberg cuando, al reflexionar sobre las partículas elementales, siente la necesidad de volverse hacia Demócrito y Platón? Daniel Barenboim, pianista y director de orquesta de fama mundial, decía buscar la integración de la música en la trama social, y no concebirla como una actividad de elites: "tenemos que concienciar a la gente de la necesidad de la educación musical como elemento orgánico de la cultura." ¿Cómo no estar de acuerdo? ¿No es acaso un ejemplo a seguir por otros componentes de la cultura?

¿Quién convencerá a los científicos, ingenieros, tecnólogos, políticos, militares, ideólogos, teólogos, filósofos y otros, sobre la necesidad de realizar un esfuerzo conjunto para integrarse y participar de manera convergente, armónica, en el desarrollo de lo humano y de su entorno, consintiendo en ser cada cual una corriente más dentro del caudal primordial de la Cultura, seno primigenio del primer hombre y de la actual Humanidad? 


\section{Notas}

${ }^{1}$ Este trabajo se basa en parte, en mi Conferencia "El Hombre, un Dilema para la Cultura y un Trastorno para la Naturaleza", dictada en Berlín en el Instituto Iberoamericano, el 17 de Febrero de 1993. $Y$, en parte, en el ensayo publicado en la revista El Talón de Aquiles, № 5, primavera de 1997, Santiago.

2 Véase Goodwin, B. (1996). "La Biología es una Danza”. Goodwin era catedrático de biología en la Open University de Londres a la fecha de la publicación.

${ }^{3}$ Sauvage, M. (1958). Sócrates y la Conciencia del Hombre. En la p.148 cita a Descartes "Cogitationes privatae", X, 217.

${ }^{4}$ Véase Arasteh, A. Reza (1984). "Rumi, el Persa, el Sufi".

${ }^{5}$ Véase lo que se puede estimar como una trilogía de $P$. Theilard De Chardin: El Fenómeno Humano (1965), El Porvenir del Hombre (1967) y El Medio Divino (1967).

${ }^{6}$ San Pablo, Epístolas a los Corintios y Epístolas a los Efesios (Biblia de Jerusalén, Editor Desclée de Brouwer)

${ }^{7}$ Evangelio según San Mateo (Biblia de Jerusalén)

${ }^{8}$ Libro de Daniel (5, 25-28): “(...) La escritura trazada es: Mené, Mené, Tequel y Parsín. Y esta es la interpretación de las palabras: Mené: Dios ha medido tu reino y le ha puesto fin; Tequel: has sido pesado en la balanza y encontrado falto de peso; Parsín: tu reino

\section{Referencias bibliográficas}

Arasteh, A. R. (1984). Rumi, el persa, el sufi. Barcelona: Paidós. Born, M. \& Hedwig. (1971). Ciencia y conciencia en la Era Atómica. Madrid: Editorial.

Brockman, J. (ed.) (1996). La Tercera Cultura: más allá de la revolución científica. Barcelona: Tusquets.

Caillois, R. (1959). "Tras seis años de un combate dudoso". Diógenes, Año VII, № 26, junio. Buenos Aires: Editorial Universitaria.

Calvino, I. (1995). Seis propuestas para el próximo milenio. Madrid: Siruela.

Dawkins, R. (1996). "Un máquina de supervivencia". En Brockman, J. (ed.). La Tercera Cultura: más allá de la revolución científica. Barcelona: Tusquets.

Eliade, M. (1984). La búsqueda. Buenos Aires: La Aurora.

Goodwin, B. (1996). "La biología es una danza". En: Brockman, J. (ed.) La Tercera Cultura: más allá de la revolución científica. Barcelona: Editores.

Heidegger, M. (1990). Identidad y diferencia. Barcelona: Anthropos.

Itzjac de Pzhysha, I. (El lehudi). (1994). "Abraham y sus huéspedes". En Buber, M. Cuentos jasidícos. Los maestros continuadores, Tomo II. Barcelona: Paidós.

Kovacs, G. (1977). "Una nueva génesis humana. Ingeniería genética y ética". Mensaje, № 257. ha sido dividido y entregado a los medas y los persas."

${ }^{9}$ Véase Landmann, M. (1961). Antropología Filosófica.

${ }^{10}$ Iaacov Itzjac de Pzhysha (El lehudi) (1994). "Abraham y sus Huéspedes”. En Buber, M. Cuentos Jasidícos: Los Maestros Continuadores, Tomo II.

${ }^{11}$ Véanse: Eliade, M. (1984). La Búsqueda. Y Nimuendajú, Unkel Curt. (1978). Los Mitos de Creación y de Destrucción del Mundo.

${ }^{12}$ Daniel Hillis. Informático, cofundador y director científico de Thinking Machines Corporation. Me refiero a su intervención con respecto al artículo "El Yo emergente", de Francisco Varela, biólogo chileno que a la fecha de su muerte era director de investigación en el Centre National de Recherche Scientifique y profesor en l'Ecole Polytechnique de París. Véase en Brockman, J. (Ed.). (1996). La Tercera Cultura: más allá de la revolución científica. pp. 61-66.

${ }^{13}$ Véase a Steve Jones, biólogo, catedrático de genética en el Laboratorio Galton del University College de Londres. Se trata de una intervención suya sobre el artículo de Nicholas Humphrey, psicólogo e investigador decano del Darwin College de Cambridge, "El momento denso". En Brockman, J. (Ed.) (1996). La Tercera Cultura: más allá de la revolución científica. pp. 61-66.

Landmann, M. (1961). Antropología filosófica. México: UTHEA. Menajem Mendel De Kotzk. (1994). "La escalera”. En Buber, M. Cuentos jasídicos. Los maestros continuadores, Tomo II. Barcelona: Paidós.

Morin, E. (1971). La revolución de los sabios. Santiago: Editorial Universitaria.

Nimuendajú, C. (1978). Los mitos de creación y de destrucción del mundo. Lima: Riester.

Recasens Salvo, A. (1993). "Oratorium für Beobachter, erschöpften Menschen und Astronautenchor". Bamberg: Bamberger, Band 7.

Sauvage, M. (1958). Sócrates y la conciencia delhombre. Madrid: Aguilar.

Theilard de Chardin, P. (1965). El fenómeno humano. Madrid: Taurus.

(1967a). El porvenir del hombre. Madrid: Taurus.

(1967 b). El medio divino. Madrid: Taurus.

Yourcenar, M. (1991). Opus Nigrum. Madrid: Alfaguara. 